\title{
One Year in: Lessons from China's Fight Against COVID-19
}

\author{
Chen Wang ${ }^{*}$
}

Since emerging one year ago, coronavirus disease 2019 (COVID-19) has inflicted tremendous suffering on mankind and has devastated the global economy. China was the first country affected by the pandemic and promptly warned the world about this novel coronavirus on January 24, 2020 (1). Despite China's efforts to contain the initial outbreak, COVID-19 continues to rampage around the globe, claiming millions of lives in the process. Nevertheless, China's success in limiting the damage inflicted by COVID-19 on its people offers lessons for effective epidemic control and response, both with respect to the ongoing pandemic and future outbreaks of known and unknown epidemic threats.

The Chinese people responded to COVID-19 with solidarity and resilience. They have waged an epic fight against the pandemic, implementing a comprehensive and stringent set of non-pharmaceutical interventions to curb the disease. For example, Wuhan initiated lockdown immediately after health officials announced human-to-human transmission (2). In the early stage of the pandemic, China also extended the Chinese Lunar New Year holiday, using this time to impose many social distancing measures, such as school and workplace closures and discouragement of mass gatherings (3). Implementation of this "outbreakcontrol holiday" substantially dampened COVID-19's epidemic spread and bought time to research the new virus, build physical infrastructure, organize medical supplies, and deploy human resources required for long-term epidemic control (4). Fangcang shelter hospitals were also built to isolate, treat, and monitor mild cases, representing an entirely novel concept in humanity's long history of fighting against infectious diseases (5). Following China's lead, many other countries adopted a strategy of facility-based isolation of mild cases (6-7). Taken together, China's multipronged approach of social distancing measures, mass testing, effective contact tracing, quarantine of suspected cases and close contacts, facility-based isolation of all confirmed cases (including asymptomatic and mild ones), and community outreach and health education collectively fueled the successful containment of its national epidemic, saving many lives and minimizing economic harms (8-9).

The COVID-19 pandemic has triggered many changes in the global geopolitical situation and outlook. First, the pandemic has created an uncertain and potentially volatile state of affairs with respect to economic development both in China and internationally. With the virus lingering, some harbor concerns over rising protectionism and the potential for global economic downturn. Yet, increasingly, forceful calls have also emerged for solidarity, collaboration, and multilateralism. Second, the pandemic has demonstrated the importance of quality medical care for ensuring human health, economic development and wellbeing, and social stability and security. As such, it is crucial to establish an efficient system for promoting high-quality public health research and innovation in medical science and technology. Third, the pandemic has altered many people's perception and behaviors in ways that are likely to persist in the long run. In the future, people may maintain social distancing, reduce unnecessary social contact, and pursue new ways to work and shop remotely, which will in turn boost the development of the digital economy.

Looking forward, China and the global community also continue to face much uncertainty with respect to the course of the COVID-19 pandemic itself. The virus that causes COVID-19 has been mutating, and we will likely see more mutations that could lead to changes in infectivity, incubation period, transmissibility, pathogenicity, duration of viral shedding, and antigenicity in the future $(10-11)$. We may need to tailor our non-pharmaceutical and pharmaceutical interventions to new variants and constantly be alert and responsive to the ongoing pandemic. Under this uncertainty, it is crucial that our surveillance systems, policy decisions, and interventions remain based on science and professionalism.

The COVID-19 pandemic will not be the last pandemic and humans would do well to reflect on and draw lessons from the current moment in order to 
better respond to future infectious disease threats. We need to increase investment in healthcare, promote innovation in medical science and technology through efficient research and development mechanisms, improve our relationship with the environment by addressing issues such as climate change, and make an all-out effort to achieve the United Nations Sustainable Development Goals. Accomplishing these aims will ultimately provide future generations with a healthier and safer world.

doi: $10.46234 / \mathrm{ccdcw} 2021.033$

\# Corresponding author: Chen Wang, wangchen@pumc.edu.cn.

Submitted: January 29, 2021; Accepted: February 01, 2021

\section{REFERENCES}

1. Wang C, Horby PW, Hayden FG, Gao GF. A novel coronavirus outbreak of global health concern. Lancet 2020;395(10223):470 - 3 . http://dx.doi.org/10.1016/S0140-6736(20)30185-9.

2. Pan A, Liu L, Wang CL, Guo H, Hao XJ, Wang Q, et al. Association of public health interventions with the epidemiology of the COVID-19 outbreak in Wuhan, China. JAMA 2020;323(19):1915-23. http://dx.doi.org/10.1001/jama.2020.6130.

3. Chen SM, Yang JT, Yang WZ, Wang C, Bärnighausen T. COVID-19 control in China during mass population movements at New Year. Lancet 2020;395(10226):764 - 6. http://dx.doi.org/10.1016/S01406736(20)30421-9.

4. Chen SM, Chen QS, Yang WZ, Xue L, Liu YL, Yang JT, et al. Buying time for an effective epidemic response: the impact of a public holiday for outbreak control on COVID-19 epidemic spread. Engineering 2020;6(10):1108 - 14. http://dx.doi.org/10.1016/j.eng.2020.07.018.

5. Chen SM, Zhang ZJ, Yang JT, Wang J, Zhai XH, Bärnighausen PT, et al. Fangcang shelter hospitals: a novel concept for responding to public health emergencies. Lancet 2020;395(10232):1305-14. http://dx.doi.org/10.1016/S0140-6736(20)30744-3.

6. Chia ML, Chau DHH, Lim KS, Liu CWY, Tan HK, Tan YR Managing COVID-19 in a novel, rapidly deployable community isolation quarantine facility. Ann Intern Med 2020;1-6. http://dx.doi.org/10.7326/M20-4746.

7. Chen S, Chen Q, Yang J, et al. Curbing the COVID-19 pandemic with facility-based isolation of mild cases: a mathematical modeling study. J Travel Med 2020;1 - 11. http://dx.doi.org/10.1093/jtm/taaa226.

8. Horton R. Offline: COVID-19-what have we learned so far? Lancet 2020;396(10265):1789. http://dx.doi.org/10.1016/S0140-6736(20) 32584-8.

9. Prettner K, Chen SM, Kuhn M, Bloom DE. Effective pandemic management that minimises economic harm. 2021. https://voxeu. org/article/effective-pandemic-management-minimises-economicharm.[2021-1-22].

10. Nature. COVID research updates: 21 January-COVID vaccines might lose potency against new viral variants. https://www.nature.com/ articles/d41586-020-00502-w. [2021-1-21].

11. Plante JA, Liu Y, Liu JY, Xia HJ, Johnson BA, Lokugamage KG, et al. Spike mutation D614G alters SARS-CoV-2 fitness. Nature 2020. http://dx.doi.org/10.1038/s41586-020-2895-3.

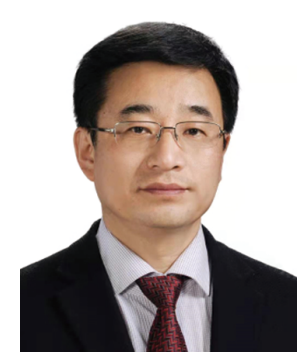

Chen Wang, MD, PhD

Vice President and Academician, Chinese Academy of Engineering President, Chinese Academy of Medical Sciences and Peking Union Medical College 